\title{
Variability of grain-filling traits in early maturing CIMMYT tropical maize inbred lines
}

Edmore Gasura, Peter S. Setimela,* Amsal Tarekegne, David Icishahayo, Richard Edema, Paul T. Gibson, and Patrick Okori

\begin{abstract}
Grain-filling rate (GFR), effective grain-filling duration (EGFD) and total grainfilling duration (TGFD) are important physiological traits of maize (Zea mays L.) grain yield (GY) formation. To devise effective breeding strategies, the genetic nature of these traits is a pre-requisite for improvement in early maturing maize. A study was conducted at CIMMYT-Zimbabwe using an $\alpha$-lattice design with two replications in two environments to investigate the genetic variability of grain-filling traits in eighteen early maturing tropical maize inbred lines derived from CIMMYT germplasm. Highly significant differences were observed for GY, 1000 grain weight (TGW), GFR, EGFD,TGFD, kernels per rows (KR) and rows per cob (RC). The broad sense coefficient of genetic determination (the fixed parent equivalent of broad sense heritability) was above $70 \%$ for all of the traits. The highest GY was obtained from the inbred line T032-30 (79.2 g plant $^{-1}$ ) and the lowest from inbred line CML506 (37.6 g plant $^{-1}$ ), respectively. Therefore, selecting for higher GFR and longer TGFD, especially the EGFD, can increase GY of early maize without extending days to physiological maturity.
\end{abstract}

E. Gasura and D. Icishahayo, Department of Crop Science, University of Zimbabwe, Box MP 167, Mt Pleasant, Harare, Zimbabwe; P.S.Setimela and A. Tarekegne, Maize Program, International Maize and Wheat Improvement Center, Box MP163, Mt Pleasant, Harare, Zimbabwe; R. Edema and P. Okori, Department of Agricultural Production, Makerere University, Box 7062, Kampala, Uganda; P.T. Gibson, Department of Plant, Soil, and Agricultural Systems, Southern Illinois University, Carbondale, Illinois, USA. Received____ * * Corresponding author (p.setimela@cgiar.org) 
1 Abbreviations: GY, grain yield; GFR, grain-filling rate; EGFD, effective grain2 filling duration; TGFD, total grain-filling duration; DPM, days to physiological maturity; TGW, 1000 grain weight, KR, kernels per row; RC, rows per cob.

Maize is the main and preferred staple food with consumption averaging $42 \mathrm{~kg}$ capita $^{-1}$ year $^{-1}$ and exceeding $100 \mathrm{~kg}$ capita $^{-1}$ year $^{-1}$ in sub-Saharan Africa (SSA)(Ninno et al., 2007; Chauvin et al., 2012). It is grown in major agro-ecological zones in southern Africa covering over 12 million hectares for more than 200 million inhabitants (FAOSTAT, 2003). However, maize yields in this region still remain low, averaging $1.4 \mathrm{t} \mathrm{ha}^{-1}$ compared to yields in developed countries (FAOSTAT, 2010). The crop is produced either as a late or early maturing crop depending on the agroecological conditions. Early maturing maize varieties provide early harvests after a long dry season and thus are an ideal crop for food security (Langyintuo and Setimela, 2007). Not only does it provide food early in the season, but it also escapes late season drought, making it suitable for early or late planting depending on the onset of rains. The term 'early maturing maize' is used relatively to refer to maize varieties that take up to 65 days to $50 \%$ anthesis and 130 days to reach physiological maturity (Magorokosho et al., 2009).

Early maturing maize is characterised by shorter plant height, less number of leaves, early maturing and a shorter total grain-filling duration (TGFD) and low grain yield (GY) in comparison to late maturing ones. The maturity period is influenced by heat units or growing degree days which have been adopted universally to classify maturity groups in maize and other crops (Dwyer et al., 1999). However, yield differences in maize varieties that take the same number of days to physiological maturity have been reported by several researchers (Magorokosho et al., 2009; 
1 Pswarayi and Vivek, 2008). This raises the possibilityof improving yield capacity of early maturing maize varieties to meet the increasing demand for maize.

Maize improvement has resulted in gains as much as $144 \mathrm{~kg} \mathrm{ha}^{-1}$ year $^{-1}$ in tropical maize under drought when stress was imposed at flowering (Edmeades et al., 1999). In temperate germplasm, the progress has been estimated at $73 \mathrm{~kg} \mathrm{ha}^{-1}$ year ${ }^{1}$ for mild stress (Duvick, 1977). Selection in maize has led to increases in yield; the net effect of this has been the reduction of genetic variability among germplasm (Lee and Tollenaar, 2007), which compounds the amount of genetic gains that can be achieved through breeding (Halluaer and Mirander, 1988). Grain yield in maize is a function of grain number, size and weight (Luque et al., 2006). Grain number is determined by plant growth rate during silking and ear attributes such as the number of kernel rows and kernels per row (Andrade et al., 1999). Kernel weight is a heritable trait that is dependent on dry matter accumulation (Borras et al., 2009) and there is a positive genetic relationship between kernel growth rate (grain-filling rate) and grainfilling duration (Talbert et al., 2001; Borras et al., 2009). Grain-filling duration starts after fertilisation and continues until physiological maturity (Lee and Tollenaar, 2007). Genotypic variability in the length of the TGFD has been reported in maize (Wang et al., 1999; Gambin et al., 2007; Borras et al., 2009). Therefore, increasing the TGFD in early maize without extending the days to maturity can help to increase yield due to the long period available for the accumulation of photo-assimilates. However, this requires screening of the tropical maize inbred lines for the variability in TGFD before evaluating the heritability of this trait. Grain yield in cereals depends of the total amount of dry-matter accumulation in the grains during the grain-filling period. However, grain-filling occurs in three stages: lag phase (rapid cell division and differentiation), linear phase (rapid dry 
1 matter accumulation) and final phase (maturation drying). Over $90 \%$ of the total dry

2 matter in the grain is accumulated during the linear phase (Lee and Tollenaar, 2007).

3 The length of the linear grain-filling phase is therefore considered the effective grain-

4 filling duration (EGFD), while the rate of dry matter accumulation during this linear

5 phase is called the grain-filling rate (GFR). The EGFD is more important because

6 over $90 \%$ of the dry matter is accumulated during this period. Grain-filling rate (GFR)

7 is measured during the EGFD, starting about two weeks post-fertilisation and is

8 highly heritable in maize (Wang et al., 1999) and other cereals such as wheat

9 (Mashiringwani et al., 1994).

Understanding the physiological mechanisms that determine crop growth and

11 increased yield is a pre-requisite for plant breeders to develop screening tools to 12 improve genotypic selection in target environments (Andrade et al., 2005). One of the 13 physiological traits,GFR, is known to be influenced by the accumulation of photo14 assimilates (source factors) and their partitioning (sink factors) and the interactions 15 between the source and sink factors (Lee and Tollenaar, 2007). These sink and source 16 attributes have been used as indirect selection for improving yields of various crops 17 (Lee and Tollenaar, 2007). Indirect selection using traits with high heritability and 18 correlation with a complex trait such as GY is more effective. In maize, genetic 19 variability for grain-filling traits have not been fully exploited to improve 20 productivity, particularly GFR, EGFD and TGFD.

21 Maize inbred lines represent a fundamental resource for studies in genetics 22 and breeding and are used extensively in hybrid maize production (Anderson and 23 Brown, 1952). Knowledge of genetic diversity in maize germplasm helps to ensure 24 that a broad genetic base of breeding materials is maintained, not just for sustaining 25 genetic improvement but also for reducing genetic vulnerability to various stresses. 
1 They can help maize breeders in efficiently assigning lines to heterotic groups and

2 guide them in the choice of parents for the development of new hybrids. Both

3 conventional and molecular breeding approaches depend on genetic variability for the

4 trait of interest. The aim of this study was to determine the genetic variability of

5 grain-filling traits in early maturing tropical maize inbred lines.

MATERIALS AND METHODS

\section{Plant materials}

Eighteen elite maize inbred lines from CIMMYT Zimbabwe tropical breeding program were selected based on earliness, drought and disease tolerance, and overall

11 adaptation to Zimbabwe.

\section{Trial management and experimental design}

The trials were conducted at CIMMYT-Zimbabwe station located at an

15 altitude of $1,500 \mathrm{~m}$ above sea level and longitude and latitude of $31^{\circ} \mathrm{E}$ and $17^{\circ} 43^{\prime} \mathrm{S}$, respectively. The mean annual rainfall exceeds $700 \mathrm{~mm}$, mostly occurring during a single growing season that ranges from early November to mid-April each year. The field experiments received $350 \mathrm{~kg} \mathrm{ha}^{-1}$ of basal fertiliser, compound D with NPK ratio of 7:14:7 and a top-dressing of $300 \mathrm{~kg} \mathrm{ha}^{-1}$ ammonium nitrate with $37.5 \%$ N. Eighteen maize inbred lines were evaluated using an $\alpha$-lattice design with two replications. A

21 plot consisted of three rows, $4 \mathrm{~m}$ long, spaced $75 \mathrm{~cm}$ apart with $25 \mathrm{~cm}$ spacing between plants within the row in all trials. Two experiments were conducted: one

23 under irrigation, with the other under rain-fed conditions. Day was used as a unit of 24 time, instead of thermal unit, because the temperature was very moderate throughout 
1 the growing season, with little variation during the grain-filling period of the two

2 experiments $\left(27-28^{\circ} \mathrm{C}\right.$ for day and $19-20^{\circ} \mathrm{C}$ for night).

\section{Data collection}

To assess various grain-filling parameters, destructive sampling was performed weekly by the removal of developing maize cobs, starting two weeks after pollination. In each plot, plants from which developing cobs were removed were left standing to maintain the initial plant density. From each sampled cob, $10 \mathrm{~g}$ of grain (fresh weight) was obtained from the middle part of the cob to reduce variation that might result from sampling different parts of the same cob. Dry weights were measured after drying the grains in a forced-air oven at $80^{\circ} \mathrm{C}$ for $96 \mathrm{~h}$. The same procedure was repeated weekly until the crop reached physiological maturity, as indicated by the formation of a black layer at the point where the kernel is attached to the cob. At physiological maturity there was no further increment in grain weight.

\section{Statistical Analyses}

A log-linear equation $\mathrm{Y}=\mathrm{b} \ln (\mathrm{x})+\mathrm{a}$, was fitted on the data, where ' $\mathrm{Y}$ ' is the percentage of dry matter at sampling time $x$, ' $b$ ' is the slope of the curve (rate of percentage dry matter increase on a log scale) and ' $x$ ' is the sampling point in time (weekly basis) and ' $a$ ' is the constant. The start of the linear phase is when the maize kernels reach $87 \%$ moisture content (13\% dry matter content) and the end is when the kernels reach 36\% moisture content (64\% dry matter content) (Borras et al., 2009). This equation was fitted to the weekly dry matter content data per plot to predict the start of the linear phase. The period prior to the linear phase was designated the lag phase duration. The period from the start of the linear phase until physiological 
1 maturity was considered the effective grain-filling duration (EGFD). Days to

2 physiological maturity (DPM) were recorded as the days from sowing until the

3 kernels developed a black layer at the point of their attachment to the cob. The grain-

4 filling rate (GFR) ( day $^{-1}$ ) was calculated as the final GY per plant divided by the

5 EGFD. The total grain-filling duration (TGFD) was calculated by subtracting the days

6 to silking from the days to physiological maturity (DPM). Data were also recorded on

7 number of kernels per row (KR), number of rows per cob (RC), and GY. The GY per

8 plant was obtained by dividing the total grain weight per plot by the number of

9 harvested cobs per plot.

Analysis of variance was conducted using Genstat software version 14

11 (Genstat, 2010) using the following mixed model as described by Dabholker(1999):

$12 \mathrm{P}_{\mathrm{ijk}}=\mu+\mathrm{g}_{\mathrm{i}}+\mathrm{t}_{\mathrm{j}}+(\mathrm{gt})_{\mathrm{ij}}+\mathrm{e}_{\mathrm{ijk}}$ where $\mu$ is the population mean, $\mathrm{g}_{\mathrm{i}}$ is the effect of the

13 inbred line $i, \mathrm{t}_{\mathrm{j}}$ is the effect of the environment $j,(\mathrm{gt})_{\mathrm{ij}}$ is the inbred line $\mathrm{x}$ environment

14 interaction effect associated with inbred linei and environment $j$, and $\mathrm{e}_{\mathrm{ijk}}$ is the within

15 environment error associated with inbred line $i$, environment $j$ and the replicate $k$. A

16 t-test was used to compare the mean performance for GY, TGW, GFR, EGFD, TGFD,

17 KR and RC between the top nine and the worst nine inbred line performers.

18 The phenotypic correlations among GY, TGW, GFR, EGFD, TGFD, KR and

19 RC were computed as described by Singh and Chaudhary (2004) as $r_{p}=$

$20\left[\operatorname{Cov}_{\mathrm{P}} /\left(\delta_{\mathrm{P}(\mathrm{X})} \delta_{\mathrm{P}(\mathrm{Y})}\right)\right]$, where $\mathrm{r}_{\mathrm{p}}$ is the phenotypic correlation between $\mathrm{X}$ and $\mathrm{Y}, \operatorname{Cov}_{\mathrm{P}}$ is

21 the phenotypic covariance between $\mathrm{X}$ and $\mathrm{Y}, \delta_{\mathrm{P}(\mathrm{X})}$ is the phenotypic standard

22 deviation of $\mathrm{X}$ and $\delta_{\mathrm{P}(\mathrm{Y})}$ is the phenotypic standard deviation of Y. The genotypic

23 correlations among traits were computed as $\left.\mathrm{r}_{\mathrm{A}}=\left[\operatorname{Cov}_{\mathrm{A}}\right) /\left(\delta_{\mathrm{A}(\mathrm{X})} \delta_{\mathrm{A}(\mathrm{Y})}\right)\right]$, where $\mathrm{r}_{\mathrm{A}}$ is the

24 genetic correlation between $\mathrm{X}$ and $\mathrm{Y}, \mathrm{Cov}_{\mathrm{A}}$ is the genetic covariance between $\mathrm{X}$ and

$25 \mathrm{Y}, \delta_{\mathrm{A}(\mathrm{X})}$ is the genetic standard deviation of $\mathrm{X}$ and $\delta_{\mathrm{A}(\mathrm{Y})}$ is the genetic standard 
1 deviation of Y. The genetic variances and covariances were obtained by subtracting

2 the error variances and covariances from their respective phenotypic variances and

3 covariances based on the 18 genotype means. Genotypic path analyses of TGW, GFR,

4 EGFD, TGFD, KR and RC on GY were calculated as described by Singh and

5 Chaudhary (2004). The assumption made for path analysis is that there are

6 unidirectional causal relationships among the yield determining traits in early maize 7 inbred lines.

8

\section{RESULTS}

There were significant differences among the maize inbred lines at $\mathrm{P}<0.001$ for GY, TGW, GFR, EGFD, TGFD, KR and RC (Table 2). The broad sense coefficient of genetic determination (the fixed parent equivalent of broad sense heritability) was above $70 \%$ for all of the traits. The inbred line by environment interaction was significant at $(\mathrm{P}<0.05)$ for $\mathrm{GY}$ and $\mathrm{GFR}$.

The highest GY was obtained from the inbred line T032-30 (79.2g plant $\left.{ }^{-1}\right)$ and the lowest from inbred line CML506 (37.6g plant ${ }^{-1}$ ), respectively (Table 3). The highest GFR (above $2.7 \mathrm{~g} \mathrm{day}^{-1}$ ) was observed in the inbred lines V547-178 and T032-30 while the longest EGFD (above 30 days) was found in the inbred lines VL057967, CML507 and VL08526. There was no significant difference in days to physiological maturity among the inbred lines. There were significant differences $(\mathrm{P}<0.05)$ between the mean of the high yielding inbred lines group and the lower yielding ones for GY, GFR, TGFD and TGW (Table 3). The group mean yield of the high yielding inbred lines exceeded the mean yield of the low yielding inbred lines by

$42.7 \%$ (3.4tha ${ }^{-1}$ vs. 2.4 tha $^{-1}$ ). Furthermore, the high yielding group had $23.6 \%$ higher 
1 GFR (2.25g day ${ }^{-1}$ vs. 1.82g day ${ }^{-1}$ ), 7.3\% longer TGFD (57.56 days vs. 53.64 days),

$2 \quad$ 10.7\% longer EGFD (non-significant) and 24.1\% more TGW (202.45g vs. 163.10g). Grain yield was significantly $(\mathrm{P}<0.05)$ positively correlated with TGW

$4 \quad(r=0.67)$, GFR ( $r=0.61)$, EGFD $(r=0.47)$ and TGFD (r=0.52) (Table 4), but less so to

$5 \mathrm{KR}$ and RC.The TGW was positively correlated with EGFD ( $\mathrm{r}=0.53$ ) and TGFD 6 ( $\mathrm{r}=0.52)$ while GFR was positively correlated with RC ( $\mathrm{r}=0.59)$ and $\mathrm{KR}$ $7 \quad(r=0.79)($ Table 4). However, GFR and EGFD were negatively correlated $(r=-0.40)$ 8 (Table 4).

The direct effects of GFR (0.93) and TGFD (0.80) on GY were positive and 10 large (Table 5), accounting for their respective positive correlation between GY 11 (Table 4). However, direct effects of TGW and KR were negligible and negative. The 12 EGFD had a negative direct effect (-0.12) on GY (Table 5) but a positive correlation 13 with GY (Table 4). However, TGFD had an indirect effect (0.35) on yield via 14 EGFD.The indirect effects of KR (0.73) and RC (0.54) on GY via GFR were positive 15 and large.

Discussion

Variability of grain yield, grain-filling traits and other related traits Improvement of GY depends on genetic variability for yield and its components. There were significant differences for GY, TGW, RC, KR, GFR, EGFD

21 and TGFD among the early maize inbred lines (Table 2), which indicated the 22 variability that breeders can exploit to improve GY of early maize. The utility of this 23 variability is evident in the best inbred lines (T032-30, VL08526, VL055063) which 24 had a combination of high GFR, longer EGFD and TGFD in addition to high TGW 25 and high kernel number $(\mathrm{RC} * \mathrm{KR})$. In line with this observation, inbred lines with the 
1 lowest yield (CML506 and CML197) either had low GFR, short EGFD or a

2 combination of these two. In this study, it is evident that the difference between the

3 high yielding and low yielding inbred lines is attributable to the differences in the

4 grain-filling traits (Table 2). The high broad sense coefficient of genetic determination

5 values of these grain-filling traits suggests the repeatability of these measurements in

6 different environments. In line with this observation, Wang et al. (1999) reported

7 significant general and specific combining ability for grain-filling traits in temperate

8 maize, thus raising possibilities of developing superior hybrids that combine long

9 EGFD and high GFR that translates into developing hybrids with high GY potential.

10 In the past, the focus on maize improvement targeted TGW and kernel number

11 (KR*RC) as indirect selection traits for improving GY (Derera et al., 2009; Banziger

12 et al., 2004; Hallauer and Miranda, 1988). However, future genetic improvements of

13 the yield of early maize must incorporate GFR, EGFD and TGFD as new potential

14 traits. Although the genotype-by-environment interaction (GEI) was significant for

15 GY and GFR, it was not present for EGFD and TGFD. The absence of GEI for EGFD

16 and TGFD shows that these grain-filling traits could be used to predict maize GY with

17 greater accuracy irrespective of the testing environment used.

\section{Relationships of grain yield, grain-filling traits and other traits}

The results showed a strong positive correlation of GY with the grain-filling

21 traits that include GFR, EGFD and TGFD. This positive correlation observed between

22 GY and grain-filling traits (GFR, EGFD and TGFD) shows the influence of these

23 traits on GY formation in maize. High GFR and longer EGFD and TGFD results in

24 the accumulation of more photo-assimilates in the grains during grain-filling (Lee and

25 Tollenaar, 2007). High rate of grain-filling also influences seed size and seed number, 
1 the two major components of GY. Longer grain-filling durations imply more dry

2 matter accumulation and hence high kernel weight that translates into high yield

3 (Gasura et al., 2013). Furthermore, increased availability of current photo-assimilates

4 reduces embryo abortion and results in high kernel numbers per cob. Kernel number,

5 size and weight are traits that largely contribute to yield (Luque et al., 2006; Andrade

6 et al., 2005). Therefore, this explains the large positive correlations observed for these

7 traits and GY suggesting their importance in GY improvement. Previous studies also

8 showed positive correlation of GFR and yield in maize (Wang et al., 1999) and wheat

9 (Mashiringwani et al., 1994). Kernel weight is determined by rate (GFR) and duration

10 (TGFD especially the EGFD) of dry matter accumulation (Andrade et al., 2005). This

11 explains the positive correlation that exists between TGW and EGFD and/or TGFD.

12 The length of the grain-filling period (EGFD or TGFD) is critical in yield formation

13 since there is no remobilisation of assimilates from the stem reserves in maize (Lee 14 and Tollenaar, 2007), unlike in rice (Yang et al., 2003), wheat (Yang et al., 2000) and 15 sorghum (Blum et al., 1997).The negative relationship between GFR and EGFD 16 observed in this study was not absolute as evidenced by some exceptional inbred lines 17 that were above the regression line. This suggests the possibility of having hybrids 18 that can combine both high GFR and longer EGFD, which may translate into high 19 yield.

21 Direct and indirect effects of grain-filling traits and other traits on grain yield

22 The GFR and EGFD had positive direct effects on GY that were larger than 23 the correlations between GY and these traits, suggesting that GFR and EGFD have a 24 true effect on GY. Singh and Chaudhary (2004) reported that if the direct effects are 25 larger than the correlations, then the indirect selection method would be the best. To 
1 this regard, GFR and EGFD become excellent traits to use in supplementing other

2 traits used to select for high GY. Large and positive direct effects of GFR and EGFD

3 on GY were also reported by Wang et al. (1999) in temperate maize germplasm. Path

4 analyses showed EGFD to have a large and indirect effect via TGFD while TGFD had

5 large indirect effect on yield via TGW. In this case, TGFD can be considered in the

6 selection for GY. The large indirect effects of KR and RC on GY via GFR show that

7 increasing KR and RC increase GFR, and in this case GFR becomes a critical trait to

8 select when improving GY.

9 In the past, maize breeders selected lines that had high kernel number (KR and 10 RC), harvest index and TGW as major yield components (Luque et al., 2006), as well 11 as improved resource capture and stress tolerance (Tollenaar and Wu, 1999; Duvick 12 and Cassman, 1999). However, it is important to consider other traits for the 13 improvement of GY. The grain-filling traits identified in this study can be used to 14 complement other traits for selection to improve GY. A better selection index can be 15 developed if GFR and EGFD are included in the equation rather than based on TGW, $16 \mathrm{KR}$ and RC alone. The advantage of the grain-filling traits is that they still have 17 variability that be exploited compared to other traits commonly used in breeding. 18 Furthermore, the absence of GEI on EGFD and TGFD makes them more accurate in 19 predicting GY across varied environments. Lee and Tollenaar(2007) noted that not all 20 variability is useful in GY. They emphasised that there will be less variability from 21 the harvest index and other source and sink factors. However, grain-filling traits are a 22 product of the various sources and sink factors and thus present much variability that 23 can be exploited in pushing up the yield of early maturity maize. Improving the yield 24 of early maize can be achieved by selecting for a combination of high GFR and long 25 EGFD. 
The breeding progress relies on genetic variability for the traits of interest,

2 high selection intensity, high heritability of the traits of interest and their strong

3 genetic correlation with yield. Furthermore, there must be a genetic correlation

4 between yield in the selection environment and the target population of environments

5 (Falconer, 1989). This demonstrates the possible utility of GFR and EGFD duration in

6 improving yield. These traits not only showed genetic variability, but also a strong

7 genetic correlation with yield. Furthermore, they showed high broad sense heritability

8 coupled with some reports that showed that these traits are largely controlled by

9 additive gene action (Wang et al., 1999), suggesting that these traits might have high

10 narrow sense heritability values. The absence of GEI on EGFD and TGFD selection

11 of yield based on these traits is desirable since it is not influenced by the selection 12 environment.

\section{Conclusions} associations with GY in tropical early maize inbred lines. These traits could be used as additional traits in the improvement of maize GY in early maize without extending the DPM by selecting for a combination of high GFR and long EGFD. In this study, inbred lines with high GFR (V547-178 and T032-30) and long EGFD (VL057967, CML 507 andVL08526) were identified and can be used in future genetic studies.

\section{Acknowledgements}

23 We are thankful to the International Maize and Wheat Improvement 24 Centre(CIMMYT), the Regional Universities Forum for Capacity Building in 
1 Agriculture (RUFORUM) and the International Foundation for Science (IFS) for

2 financing this work.

3

\section{References}

Anderson, E., and W.L. Brown. 1952. Origin of corn belt maize and its genetic significance, In: Heterosis - A Record of Researches Directed toward Explaining and Utilising the Vigour of Hybrids, Gowen, J.W., Ed., Iowa State College Press, Ames, 124-148.

Andrade, F. H., C. Vega, S. Uhart, A. Cirilo, M. Cantarero, and O. Valentinuz. 1999. Kernel number determination in maize. Crop Sci.39: 453-459.

Andrade, F.H., V.O. Sadras, C.R., C. Vega, and L. Echarte. 2005. Physiological determinants of crop growth and yield in maize, sunflower and soybean: Their application to crop management, modelling and breeding. J. Crop Impr. 14(1): 51-101.

Banziger, M., P.S. Setimela, D. Hodson, and B. Vivek. 2004. Breeding for improved drought tolerance in maize adapted to southern Africa. New Directions for a diverse planet: Proceedings of the $4^{\text {th }}$ International Crop Science Congress 26 September-1 October 2004. Brisbane, Australia.

Blum, A., G. Golan, J. Mayer, and B. Sinmena. 1997. The effect of the dwarfing genes on sorghum grain-filling from remobilised stem reserves under stress. Field Crops Res. 52: 43-54.

Borras, L., C. Zinselmeier, M.L. Senior, M.E. Westgate, and M.G. Muszynski. 2009. Characterization of grain-filling patterns in diverse maize germplasm. Crop Sci.49: 999-1009.

Chauvin, N. D., F. Mulangu, and G. Porto. 2012. Food production and consumption trends in sub-saharan Africa: Prospects for the transformation of the agricultural 
sector. Working Paper, United Nations Development Programme, Regional Bureau of Africa.

Dabholker, A.R. 1999. Elements of Biometrical Genetics. Concept Publishing Company, New Delhi.

Derera, J., P. Tongoona, B.S. Vivek, and M.D. Laing. 2007. Gene action controlling grain yield and secondary traits in southern African maize hybrids under drought and non drought environments. Euphytica 162: 411-422.

Duvick, D.N. 1977. Genetic rates of gain in hybrid maize yields during the past 40 years. Maydica 22: 187-196.

Duvick, D.N., and K.G. Cassman. 1999. Post-green revolution trends in yield potential of temperate maize in the north-central United States. Crop Sci.39: 1622-1630.

Dwyer, L.M., B.L. Ma. L. Evenson, and R.L. Hamilton. 1994. Maize physiological traits related to grain yield and harvest moisture in mid- to short-season environments. Crop Sci. 34: 985-992.

Edmeades, G.O., J. Bolanos, S.C. Chapman, M. Bänziger and H.R. Lafitte. 1999. Selection improves water stress tolerance to mid/late season water stress in tropical maize populations. I. Gains in biomass, grain yield, and harvest index. Crop Sci.39: 1306-1315.

Falconer, D.S. 1989.Introduction to Quantitative Genetics.3rd edition.Longman Group Ltd. p 438.

FAOSTAT. 2003. FAO statistical database. FAO, Rome, Italy. www.fao.org

FAOSTAT. 2010. FAO statistical database. FAO, Rome, Italy.http://faostat.fao.org (5 June 2012). 
1 Gambin, B.L., L. Borras, and M.E. Otegui. 2007. Kernel water relations and duration of grain-filling in maize temperate hybrids. Field Crops Res. 101: 1-9.

3 Gasura, E., P. Setimela., R. Edema., P.T. Gibson., P. Okori, and A. Tarekegne. 2013. Exploiting grain-filling rate and effective grain-filling duration to improve grain yield of early maturing maize. Crop Sci.53:1-9.

$6 \quad$ Genstat Release 14 (2010). VSN International Ltd.

Hallauer, A.R., and J.B. Miranda. 1988. Quantitative Genetics in Maize Breeding, 2nd Ed. Iowa State University Press, Ames. CIMMYT.

Lee, E.A., and M. Tollenaar. 2007. Physiological basis of successful breeding strategies for maize grain yield. Crop Sci. 47: 202-215.

Luque, D.F., A.G. Cirilo, and M.E. Otegui. 2006. Genetic gains in grain yield and related physiological attributes in Argentine maize hybrids. Field Crops Res 95: 383-397.

Magorokosho, C., B. Vivek, and J. MacRobert. 2009. Characterization of maize germplasm grown in eastern and southern Africa: Results of the 2008 regional trials coordinated by CIMMYT. CIMMYT, Harare.

Mashiringwani, N. A., K. Mashingaidze, J. Kangai and K. Olsen. 1994. Genetic basis of grain-filling rate in wheat (Triticumaestivum L. emend. Thell.)Euphytica 76(2): 33-44.

Ninno, C., P. A. Dorosh, and K. Subbarao. 2007. Food aid, domestic policy and food security: Contrasting experiences from south Asia and sub-Saharan Africa. Food Policy 32: 413-435 
1 Pswarayi, A., and B. Vivek. 2008. Combining ability amongst CIMMYT's early

2 maturing maize (Zea mays L.) germplasm under stress and non-stress conditions

3 and identification of testers. Euphytica 162: 353-362.

4 Singh, R.K., and B.D. Chaudhary. 2004. Biometrical Methods in Quantitative Genetic Analysis. Third ed. Kalyani Publishers, New Delhi.

6 Stewart, D.W., L.M. Dwyer, and L.L. Carrigan. 1998. Phenological temperature response of maize. Agron. J. 90: 72-79.

8 Talbert, L.E., S.P Lanning, R.L. Murphy, and J.M. Martin. 2001. Grain-filling 9 duration in twelve hard red spring wheat crosses: Genetic variation and association with other agronomic traits. Crop Sci.41: 1390-1395.

11 Tollenaar, M., and J. Wu. 1999. Yield improvement in temperate maize is attributable to greater stress tolerance. Crop Sci.39: 1597-1604.

13 Wang, G., M.S. Kang, and O. Moreno. 1999. Genetic analyses of grain-filling rate and duration in maize. Field Crops Res. 61: 211-222.

15 Yang, J., J. Zhang, Z. Huang, Q. Zhu, and L. Wang. 2000. Remobilisation of carbon 16 reserves is improved by controlled soil-drying during grain-filling of wheat. Crop Sci.40: $1645-1655$.

18 Yang, J., J. Zhang, Z. Wang, L. Liu, and Q. Zhu. 2003. Post-anthesis water deficits 19 enhance grain-filling in two-line hybrid rice. Crop Sci.43: 2099-2108. 
2 Table 1.Names and pedigrees of the CIMMYT maize inbred lines used in this study

3

\begin{tabular}{ll}
\hline Inbred line name & Inbred line pedigree \\
\hline T032-30 & ZEWAc2F2-183-2-B-B-B \\
VL08526 & ZEWBc2F2-101-2-B \\
VL055063 & [Ent320:92SEW2-77/[DMRESR-W]EarlySel-\#I-2-4-B/CML386]-B-11-3-B-2-\#-B*4 \\
VL057967 & ZEWAc1F2-219-4-3-B-1-B*4-2-4 \\
C389-92 & ZM523B-29-2-1-1-B*6 \\
VL05615 & ZEWBc1F2-216-2-2-B-2-B*4-2-4 \\
VL057903 & ZEWAc1F2-151-6-1-B-1-BBB-2-6 \\
VL0536 & [CML389/CML176]-B-29-2-2-B*5 \\
VL08528 & ZEWBc2F2-110-1-B \\
CML507 & [[[K64R/G16SR]-39-1/[K64R/G16SR]-20-2]-5-1-2-B*4/CML390]-B-38-1-B-7-\#-B*6 \\
V547-178 & 03SADVEA-\#-28-1-2-1-1-B \\
VL057847 & ZEWAc1F2-300-2-2-B-1-B*4-3-4 \\
VL0536 & [CML389/CML176]-B-29-2-2-B*5 \\
VL05128 & WWO1408-1-1-2-B*4-\#-B \\
CML508 & [89[G27/TEWTSRPool]\#-278-2-X-B/[COMPE2/P43SR//COMPE2]F\#-20-1-1]-B-32-2-B-4-\#-2-B*5 \\
VL058014 & ZEWAc1F2-254-2-1-B-1-BBB \\
CML197 & Ent52:92SEW1-2/[DMRESR-W]EarlySel-\#L-2-1-B/CML386]-B-22-1-B-4-\#-1-B*5-B-B \\
CML506 & {$[$ EarlyMid1/KatumaniSR]-\#-169-2-4-B-1-\#-BBB } \\
\hline
\end{tabular}


2 Table 2. Summary ANOVA, variance components and broad sense heritability values

\begin{tabular}{|c|c|c|c|c|c|c|c|c|}
\hline Source & $\mathrm{DF}$ & $\begin{array}{l}\text { Grain Yield } \\
\left.\text { (g plant }^{-1}\right)\end{array}$ & $\begin{array}{l}{ }^{\mathrm{a}} 1000 \text { kernel } \\
\text { weight }(\mathrm{g})\end{array}$ & $\begin{array}{l}\text { Grain filling rate } \\
\left(\text { g day }^{-1}\right)\end{array}$ & $\begin{array}{l}\text { Effective grain filling } \\
\text { duration (days) }\end{array}$ & $\begin{array}{l}\text { Total grain filling } \\
\text { duration (days) }\end{array}$ & $\begin{array}{l}\text { Rows per } \\
\text { cob }\end{array}$ & $\begin{array}{l}\text { Kernels per } \\
\text { row }\end{array}$ \\
\hline Environments & 1 & $2493.31 *$ & & $1.97 *$ & 28.48 & 1.13 & 2.70 & 45.71 \\
\hline Environments.Replications & 2 & 28.66 & 52.10 & 0.04 & 15.92 & 3.74 & 0.50 & 12.81 \\
\hline Genotypes & 17 & $578.13 * * *$ & $2098.10 * * *$ & $0.79 * * *$ & $80.38 * * *$ & $71.27 * * *$ & $9.80 * * *$ & $42.06 * * *$ \\
\hline Genotype*Environment & 17 & $72.66^{*}$ & & $0.24 *$ & 12.50 & 3.42 & 0.94 & 6.54 \\
\hline Error & 34 & 37.15 & 150.80 & 0.11 & 11.52 & 4.38 & 0.73 & 8.38 \\
\hline Total & 71 & & & & & & & \\
\hline Error variance component & & 37.15 & 150.80 & 0.11 & 11.52 & 4.38 & 0.73 & 8.38 \\
\hline GxE variance component & & 16.26 & & 0.07 & 0.49 & -0.48 & 0.11 & -0.92 \\
\hline Genotype variance component & & 127.12 & 973.65 & 0.14 & 16.97 & 16.96 & 2.22 & 8.88 \\
\hline \multicolumn{9}{|l|}{ Broad sense heritability } \\
\hline Single plot basis & & 0.70 & 0.87 & 0.44 & 0.59 & 0.81 & 0.73 & 0.54 \\
\hline Across envrionments basis & & 0.88 & & 0.70 & 0.84 & 0.95 & 0.90 & 0.84 \\
\hline
\end{tabular}

*** significant at $0.1 \%$ probability level, * significant at $5 \%$ probability level. ${ }^{\text {a }}$ traits recorded in one environment. 
Crop Science: Posted 27 Nov. 2013; doi: 10.2135/cropsci2013.07.0441

1 Table 3. Grain yield and related traits performance of the top nine and bottom nine yielding maize inbred lines 
Crop Science: Posted 27 Nov. 2013; doi: 10.2135/cropsci2013.07.0441

\begin{tabular}{|c|c|c|c|c|c|c|c|c|}
\hline $\begin{array}{l}\text { Inbred line } \\
\text { name }\end{array}$ & $\begin{array}{l}\text { Grain yield } \\
\text { (g plant }^{-1} \text { ) }\end{array}$ & $\begin{array}{l}1000 \text { kerne } \\
\text { weight }(\mathrm{g})\end{array}$ & $\begin{array}{l}\text { Grain filling rate } \\
\left(\mathrm{g} \mathrm{day}^{-1}\right)\end{array}$ & $\begin{array}{l}\text { Effective grain filling } \\
\text { duration (days) }\end{array}$ & $\begin{array}{l}\text { g Total grain filling } \\
\text { duration (days) }\end{array}$ & $\begin{array}{l}{ }^{\text {a }} \text { Days to physiological } \\
\text { maturity (days) }\end{array}$ & $\begin{array}{l}\text { Rows per } \\
\text { cob }\end{array}$ & $\begin{array}{l}\text { Kernels per } \\
\text { row }\end{array}$ \\
\hline \multicolumn{9}{|c|}{ 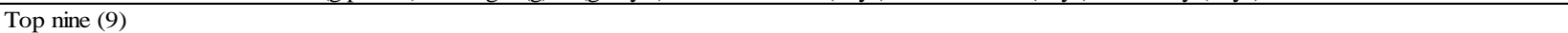 } \\
\hline T032-30 & 79.22 & 224.98 & 2.76 & 28.64 & 57.50 & 122.00 & 12.83 & 23.08 \\
\hline VL08526 & 76.46 & 210.47 & 2.38 & 32.38 & 60.75 & 127.00 & 13.50 & 24.83 \\
\hline VL055063 & 67.74 & 169.09 & 2.42 & 28.52 & 54.25 & 127.00 & 14.33 & 25.92 \\
\hline VL057967 & 64.85 & 211.79 & 1.94 & 33.65 & 59.75 & 128.00 & 10.90 & 22.83 \\
\hline V553/1 & 59.69 & 181.17 & 2.45 & 24.51 & 53.50 & 125.00 & 16.67 & 23.17 \\
\hline VL05615 & 58.31 & 158.47 & 2.27 & 25.92 & 58.25 & 128.00 & 15.83 & 22.25 \\
\hline VL057903 & 57.83 & 240.14 & 2.02 & 29.92 & 62.75 & 127.00 & 13.08 & 16.76 \\
\hline CML509 & 54.26 & 245.08 & 1.95 & 27.97 & 55.00 & 127.00 & 11.50 & 18.17 \\
\hline VL08528 & 54.21 & 180.83 & 2.08 & 26.70 & 56.25 & 127.00 & 12.17 & 23.75 \\
\hline Mean & 63.62 & 202.45 & 2.25 & 28.69 & 57.56 & 126.44 & 13.42 & 22.31 \\
\hline Standard deviation & 9.22 & 31.35 & 0.28 & 2.95 & 3.12 & 1.88 & 1.91 & 2.98 \\
\hline \multicolumn{9}{|l|}{ Bottom nine (9) } \\
\hline CML507 & 52.05 & 190.75 & 1.60 & 32.51 & 57.00 & 131.00 & 11.00 & 17.00 \\
\hline V547-178 & 48.49 & 147.37 & 2.90 & 17.16 & 55.00 & 120.00 & 12.67 & 26.33 \\
\hline VL057847 & 47.97 & 184.07 & 1.52 & 31.62 & 57.00 & 129.00 & 12.00 & 23.75 \\
\hline VL0536 & 44.38 & 138.65 & 1.64 & 27.21 & 49.25 & 130.00 & 13.33 & 22.58 \\
\hline VL05128 & 43.75 & 169.82 & 2.09 & 21.23 & 44.50 & 127.00 & 12.83 & 24.58 \\
\hline CML508 & 43.16 & 167.68 & 1.40 & 31.11 & 54.50 & 127.00 & 12.50 & 17.75 \\
\hline VL058014 & 42.89 & 168.07 & 1.67 & 25.72 & 54.25 & 122.00 & 10.83 & 16.25 \\
\hline CML197 & 41.12 & 143.24 & 2.18 & 20.10 & 58.75 & 127.00 & 13.17 & 22.08 \\
\hline CML506 & 37.58 & 158.22 & 1.40 & 26.68 & 52.50 & 127.00 & 12.00 & 20.25 \\
\hline Mean & 44.60 & 163.10 & 1.82 & 25.93 & 53.64 & 126.67 & 12.26 & 21.18 \\
\hline Standard deviation & 4.32 & 17.88 & 0.49 & 5.45 & 4.41 & 3.57 & 0.89 & 3.57 \\
\hline Difference & 19.02 & 39.35 & 0.43 & 2.76 & 3.92 & -0.22 & 1.16 & 1.13 \\
\hline \% Difference & 42.65 & 24.13 & 23.63 & 10.66 & 7.30 & -0.18 & 9.50 & 5.34 \\
\hline Standard error of difference & 3.39 & 12.03 & 0.19 & 2.07 & 1.80 & 1.34 & 0.70 & 1.55 \\
\hline t-value & 5.60 & 3.27 & 2.30 & 1.34 & 2.17 & -0.17 & 1.66 & 0.73 \\
\hline t-probability & 0.000 & 0.005 & 0.035 & 0.200 & 0.045 & 0.871 & 0.117 & 0.476 \\
\hline Minimum value & 9.22 & 31.35 & 0.28 & 2.95 & 3.12 & 120.00 & 1.91 & 2.98 \\
\hline Mean & 54.11 & 182.80 & 2.04 & 27.31 & 55.60 & 126.56 & 12.84 & 21.74 \\
\hline Maximum value & 79.22 & 245.08 & 2.90 & 33.65 & 62.75 & 131.00 & 16.67 & 26.33 \\
\hline P-value (for 18 inbred lines) & $<.001$ & $<.001$ & $<.001$ & $<.001$ & $<.001$ & & $<.001$ & $<.001$ \\
\hline $5 \%$ least significant difference & 12.28 & 25.37 & 0.65 & 6.97 & 4.23 & & 1.72 & 5.96 \\
\hline Coefficient of variation (\%) & 11.30 & 6.70 & 16.00 & 12.40 & 3.80 & & 6.60 & 3.90 \\
\hline
\end{tabular}


${ }^{a}$ traits recorded in one replication of one environment.

Table 4. Genotypic (lower diagonal) and phenotypic (upper diagonal) correlation coefficients of grain yield and yield determining traits

\begin{tabular}{|c|c|c|c|c|c|c|c|}
\hline & $\begin{array}{l}\text { Grain Yield } \\
\left.\text { (g plant }^{-1}\right)\end{array}$ & $\begin{array}{l}1000 \text { kernel } \\
\text { weight (grams) }\end{array}$ & $\begin{array}{l}\text { Grain filling rate } \\
\left(\mathrm{g} \mathrm{day}^{-1}\right)\end{array}$ & $\begin{array}{l}\text { Effective grain filling } \\
\text { duration (days) }\end{array}$ & $\begin{array}{l}\text { Total grain filling } \\
\text { duration (days) }\end{array}$ & $\begin{array}{l}\text { Rows per } \\
\text { cob }\end{array}$ & $\begin{array}{l}\text { Kernels per } \\
\text { row }\end{array}$ \\
\hline Grain yield (g plant ${ }^{-1}$ ) & 1.00 & 0.60 & 0.61 & 0.42 & 0.49 & 0.28 & 0.34 \\
\hline 1000 kernel weight (grams) & 0.67 & 1.00 & 0.11 & 0.55 & 0.49 & -0.23 & -0.29 \\
\hline Grain filling rate $\left(\mathrm{g}_{\text {day }}{ }^{-1}\right.$ ) & 0.61 & 0.15 & 1.00 & -0.44 & 0.18 & 0.49 & 0.61 \\
\hline Effective grain filling duration (days) & 0.47 & 0.53 & -0.40 & 1.00 & 0.43 & -0.28 & -0.32 \\
\hline Total grain filling duration (days) & 0.52 & 0.52 & 0.21 & 0.45 & 1.00 & -0.04 & -0.18 \\
\hline Rows per cob & 0.30 & -0.21 & 0.59 & -0.34 & -0.07 & 1.00 & 0.41 \\
\hline
\end{tabular}


Table 5. Direct and indirect effects of grain-filling and related traits on grain yield

\begin{tabular}{|c|c|c|c|c|c|c|}
\hline & weight (grams) & $\left(\right.$ g day $\left.^{-1}\right)$ & duration (days) & duration (days) & $\mathrm{cob}$ & row \\
\hline 1000 kernel weight (grams) & -0.02 & 0.00 & -0.01 & -0.01 & 0.01 & 0.01 \\
\hline Grain filling rate $\left(\mathrm{g} \mathrm{day}^{-1}\right.$ ) & 0.14 & 0.93 & -0.37 & 0.20 & 0.54 & 0.73 \\
\hline Effective grain filling duration (days) & -0.06 & 0.05 & -0.12 & -0.05 & 0.04 & 0.05 \\
\hline Total grain filling duration (days) & 0.41 & 0.17 & 0.35 & 0.80 & -0.06 & -0.16 \\
\hline Rows per cob & -0.02 & 0.06 & -0.03 & -0.01 & 0.10 & 0.04 \\
\hline Kernels per row & 0.03 & -0.06 & 0.04 & 0.02 & -0.03 & -0.08 \\
\hline
\end{tabular}

3 